\title{
Vitoria y la expansión de la Iglesia
}

\author{
Por el Presbítero FIDEL TUBINo \\ Catedrático de la Universidad Católica
}

\section{Proemio:}

Hay una entidad jurídica, que ha desconcertado a los altores internacionalistas: la Iglesia, sujeto de relaciones con los Estados. Cuando en 1870 cayó el poder temporal que cubría su verdadero carácter, estaban en auge las fórmulas del positivismo con la adoración del estado, cuya vo luntad dá origen al derecho interno, cuya autolimitación hace posible el derecho internacional. Las varias corrientes, positiva, sociologica y neokantiana converían en un fondo común, más o menos explícito: la estatalidad del derecho. Fuera del estado o de los estados, no había norma jurídica, sino meras relaciones morales.

Pero en los últimos tiempos se revoluciona la vida internacional: surgen organismos interestatales, que carecen de la base territorial y desempeñan funciones propias del derecho: la Comisión del Danubio, la Cor te de la Haya, la Sociedad de Naciones... La doctrina había puesto como piedra de toque, el hecho real; luego, frente a los hechos había que revisar las fórmulas estrechas del monopolio juridico a favor del estado.

Así por los moldes positivos, sin atención a sus prerrogativas intrínsecas, la Iglesia Católica viene de nuevo admitida en el regazo de los seres jurídicos internacionales, $y$, nótese bien antes del surgir del Estado Vaticano por los protocolos de Letrán. Anzillotti, corifeo del positivismo italiano, había negado dicha sujetividad jurídica en dos primeras ediciones, de su tratado de Derecho Internacional pero en la tercera confiesa que los pactos de la Iglesia, si se quiere mirar la realidad, están en la misma condición de los tratados y por consiguiente suponen una persona jurídica.

En nuestros días se manifiesta en el positivismo jurídico y en las corrientes de carácter formalista kantiano un ambiente propicio para resolver de una manera completa la complejidad de la Iglesia. Otro positivista italiano, Santi Romano, concibe el derecho como compuesto de zonas que tienen dominio y valor, cada una en su campo; asi vale el derecho canónico, como el civil; luego de la yústaposición de estas esferas surge un derecho de orden superior. Por otra parte el apriorismo de Kant, 
ha llegado a su remate con la doctrina de Kelsen, según el cual todo el orden jurídico depende de un principio metajurídico sin contenido, pues el contenido es el fenómeno histórico; ahora bien, en la actualidad las relaciones diplomáticas ponen a la Iglesia a la par que los estados; luego, también para los sucesores de Kant ésta puede alcanzar personalidad.

Pero, ¿no habrá fórmula y principios que hayan resuelto mejor, es decir con base más sólida, las complicaciones que este organismo mediomoral, interiorista y extramundano acarrea? Creemos que sí; y precisamente queremos presentar a un representante de esta tendencia a la cual adherimos; es Francisco Vitoria. $\mathrm{Ni}$ es retroceder en la ciencia, porque, como esperamos demostrar en un problema particular, él aplicó criterios nuevos a los hechos nuevos, esos hechos, como el descubrimiento de América, los cuales son el principio de la Edad moderna.

Es una fatalidad histórica por cierto, muy deplorable, que la ruptura político-religiosa producida por la Reforma trajese consigo el aislamiento de dos pujantes polos culturales, el mundo germánico y el español y como consecuencia que las doctrinas filosóficas y jurídicas de la escuela española se agotaran dentro de la península ibérica y no contribuyeran casi nada en la cultura internacional de los siglos XVI y siguientes. Grocio conoció la obra de Vitoria, pero con sentido muy diverso trazó un rumbo distinto, ese falso jusnaturalismo, que desarrollado por el iluminismo ha llevado al individualismo jurídico actual amoral y laico y al fracaso de las doctrinas internacionales.

No es, por tanto, un afán de pasado la pretensión de estas líneas. es el porvenir. Hacer conocer las Relecciones del español interesa, diré con Getino, (1) "más que como reviviscencia de una obra clásica de gran influjo en el pasado, como alimento indispensable de las generaciones selectas actuales, ansiosas de dulcificar las relaciones internacionales".

Creo que Vitoria bajo su ropaje antiguo resuelve con intuición de moderno muchos de esos problemas de intervención, exigencias fundamentales de los estados, que acucian a los teóricos de hoy. En Vitoria hallarán fórmulas amplias, racionales y justas.

Entre los extremos de la adoración del mero hecho concreto y del apriorismo de principios. que fundamenten con justicia, ha renacido ya en los varos países de Furopa, la corriente cue sostiene ser ei derecto la concreción tictórira de exigencias fundadas en la mouraleza del hombre. A ésta Vitoria le enseñará desde lejos cómo los problemas actuales pueder hallar una completa solución.

Notas preliminares.

El problema que nos ha de ocupar es el siguiente: iqué pensó Vitoria y qué puede deducirse de sus principios acerca de la expansión vital de la lolesia en un estado no católico o, en general, en el estado?. Hay Wos cuestiones: la primera qué posición ruarda un tercer estado católico delegado por la lolesin frente a ésta y al estado no católico. y la segunda, qué prerrogetivas puede traer a colación la Iglesin, como derechos fundameniales, frente al estado no cristiano en materia de expansión religiosa.

For consicuiente, la investigación es exclusivamente jurídica y prescinde del hecho histórico que dío a Vitoria ocasión de escribir sus Relec- 
ciones "De Indis", la conquista del Perú. Antecede una parte de ambientación sociológica para que se pueda comprender el valor del personaje.

Tiene además este ensayo una aspiración: traducir en lenguaje técnico moderno las concepciones del maestro escolástico. Sus líneas serán el material del cual serán extraídas las figuras del derecho internacional moderno mediante un trabajo de interpretación, así como los tecnicismos de una cultura médica interpretan equivalentemente las nociones de los hombres, también cultos pero profanos. Se trata, pues, de juntar los principios de Vitoria y sacar, aún por nuestra cuenta, sus conclusiones:

Por razones prácticas me limito a la Relección "De Indis prima" y a las partes pertinentes de la "De potestate Ecclesiae prima". También prescindo de la cuestión sobre la originalidad de las doctrinas, y me ceñiré al examen directo del texto. Si pudiera darse un título colorista a estas líneas, sería: modernidad de Vitoria demostrada a través de un problema moderno de muy difícil solución: la actividad expansiva de la lglesia dentro del organismo estatal.

\section{LA SILUETA DE VTTORIA}

La actividad de Vitoria se concentra en la primera parte del siglo XVI. No será inútil recorrer a grandes rasgos las líneas de su vida y enfocar el envolvente cultural en que debió actuar.

Nace Francisco de Vitoria, en la ciudad alavesa de la que lleva el nombre por los años de 1480. Viste el hábito de la Orden de los Predicadores en el Convento de San Pablo de Burgos, y descollando por su ingenio es mandado, en la primera década del siglo, a París, que aún conserva la hegemonía teológica. Allí escucha al maestro dominíco Pedro Crockaert Bruxellensis, uno de los grandes comentadores pretridentinos de S. Tomás, traba relaciones con Erasmo de Rotterdam y con Juan Luis Vives, y allí mismo comienza su tarea de maestro. Son unos dieciocho años de vida parisiense.

Cuando vuelve a su tierra española. Vitoria, después de una breve enseñanza en Valladolid (hasta 1526), escala de golpe, desbancando a competidores más ancianos y muy acreditados, la cátedra de Prima, que era la más importante en la enseñanza Teológica, en el Convento de San Esteban de Salamanca. Comienza desde entonces la gran obra de renovación de la ciencia y la forja de la intelectualidad no sólo teológica, sino jurídica y social.

Vitoria enseñó Teología, y ello, lejos de ser una rémora fué motivo que en sus "Relecciones" abarcara los problemas de moral política y de iactualidad internacional, el asunto de Indias, que él bien conocía, aún en su parte de hecho, por recibir relaciones directas de los misioneros, y que dominaba en sus nuevos aspectos de derecho por las consultas de moral qụe se le hacían. Pero principalmente el Maestro fué teólogo, y en este cámpo ejerció su actividad y sus reformas. Fué él quien sustituyó a los antiguos textos, la Suma como libro de aprendizaje. (Crabmann, Historia de la Teología Católica, pág. 102).

Vitoria no publicó sus obras, redactó sí para completar la tarea de maestro algunas partes de su enseñanza, pero sin miras a ìa publicidad. bus famosas Relecciones presentan varias redacciones, debidas a sus alum- 
nos, quizás confrontadas con un original del maestro. Nos consta que en su explanación oral, a veces se salía del texto escrito, aun cuando fuese por extenso (asi parece ser en las Relecciones), y ampliaba lo que había sólo bosquejado por escrito. Esto explica ciertas aparentes contradicciones de detalle de sus obras, consecuencias de escribir por esquema.

Los frutos fueron opimos. "De Vitoria data la verdadera renovación en los estudios teológicos de España y la soberana importancia que la Teología, convertida en ciencia universal que abarca desde los atributos divinos hasta las últimas ramificaciones de? derecho público y privado, llegó a ejercer en nuestra vida nacional. haciendo de España un pueblo de teólcgos. Un abismo separa todo la teología española anterior a Francisco de Vitoria, de la que él enseñó y profesaba, y los maestros que después de él vinicron, valen más o menos en cuanto se acercan o se alejan de sus ejemplos y de su doctrina. Todo el asombroso florecimiento teológica de nuestro siglo XVI, estaba contenido en germen, en la doctrina del Sócrates alavés" (2). Discipulos fuezon Melchor Cano y Dominen de Soto; de su encuela fueron Bañez y Francisco de Toledo. los Covarubias y Ledesma, Vega, Pedro de Soto, Tude'n, Mnáles y michos más. Así ese hombre, de cuerpo molido por los achaques, que en los últimos tiempos debía ser llevado de peso hasta la cátedra, con el vigor de su lengua, organizó una mitura y cré un competidor temible a la Universidad parisiense. Nombrado teólogo del emperador Carlos Y para el Concilio de Trento. no pudo asistir por su estado de salud; pero siempre sin abandonar su cátedra interviene en los acontecimientos sociales de entonces con las numerosas consultas, que de toda parte llovían: el Papa en la espinosa cuestión del repudio de Catalina de Aragón, los peruleros por las nuevas riquezas. En una palabra, el vigor de una inteligencia privilegiada fue deste una aula el que enrumbó con derroteros nuevos muchos problemas sociológicos de su época. Murió el 11 de agosto de 1546, cuando se encendían en Trento, a la mirada de toda la ciencia mundial, los fulgores de la Teología española

\section{LOS TIEMPOS DE VITORIA}

Vitoria había propugnado el magisterio de Santo Tomás; pero él comprendía que la evolución de los tiempo requería nuevos desarrollos. El español se preocupaba con preferencia por los problemas morales y jurídicos de la vida social, y ésta era profundamente diversa de la del Aquinate, hasta contradictoria. Las realidades externas caían y las doctrinas buscaban una orientación moderna.

En los tiempos de Santo Tomás, era un hecho la concepción piramidal de la vida social, cuyo vértice era el papado. Durante el siglo XIV surgió, principalmente a raíz de la contienda política de Bonifacio VIII y Felipe de Francia, la controversia ideológica acerca de los límites de las dos potestades. Por una parte, el canónigo Marsilio de Padua, verdadero precursor de los wiclefitas y pseudoreformadores, sometía la estructura jurídica eclesiástica al poder imperial; por la otra, los curialistas, desde Egidio Romano hasta Alvaro Pelagio, decían que así como Dios es uno, así también lo es la vida social, y su jefe el Papa, único depositario de la autoridad. En la línea de los hechos los desastres politicos de Luis de Bavie- 
ra y la insubordinaçión de los príncipes habían desecho la autoridad imperial. La captividad aviñonesa había quitado al Pontífice el lustre de árbitro internacional. La ciencia especulativa en decadencia, por las sutilezas vacías de las distinciones y por las teorías del nominalismo.

Cuando aparecía Vitoria en escena, ya se habían consolidado los gérmenes de la nueva sociedad. La nueva creatura del Renacimiento, el estado, tenía su carta de plena ciudadanía autónoma en el Derecho canónico, desde que Torquemada deslindando definitivamente derechos, había consolidado las bases de ambas potestades, fijando la sujeción meramente indirecta del poder civil a la Iglesia. Francia era un estado que negaba abiertamente toda dependencia del Imperio. España, verdadero portento, había nacido adulta y armada como Minerva del cerebro de un Dios, tejiéndose en América una corona real más dominadora que el cetro del Sacro Imperio germano. El gran acontecimiento de la historia moderna, la colonización del Nuevo Mundo, le daba un imperio extensísimo y le creaba problemas jurídicos a su legitimismo moral. Era esta su preocupación más honda y absorbente en el desborde primero de su pujanza, y ansiaba fómmulas que tuviesen comprensión de sus ímpetus. Fuera de España, por esos mismos años en que Vitoria subía la cátedra salmantina, Lutero había desecho la unidad religiosa de Europa y había desencadenado la lucha social en Alemania. Ni pudo contemplar nuestro autor la restauración Tridentina, pues al año siguiente de la apertura del Concilio (1546), moría. Frente a tanto desbarajuste, ¿sabría el maestro, que vivía lentre libros, interpretar las exigencias nuevas e impulsar el aspecto vita! sano de las corrientes que nacían, reconociendo lo que había de legítimo en ellas y de decrépito en la tradición?

\section{VITORIA, DEMOLEDOR}

Vitoria parece querer desembarazarse hasta con brusquedad de las dos creaturas que habían regulado la vida de la Edad Media, el supuesto poder universal del Imperio y del Papado, como atributos inherentes a la naturaleza. No podemos fijar con certeza el texto literal de algunas frases, demasiado tajantes, que pueden atribuirse a los discípulos copistas de las Relecciones, pero el pensamiento del Maestro es claro: la sociedad política medieval, llámese Papado o Imperio, no tenía poder sobre los estados que estaban fuera de ella (Vitoria habla de los Indios americanos). El imperio era un fenómeno histórico positivo; había nacido, se habia fraccionado en partes, cuando el Papa trasladó la corona de Occidente a los ger. manos (pág. 31-39) (3). Estaba condicionado en su entensión, que podía aumentar o disminuir. Vitoria nos dice textualmente que ni Francia ni España estaban bajo su poder, y admite como causa normal de su reducción, la prescripción según pasó en la época de las Ciudades libres. 'Así también es un absurdo imaginar una entidad universal que por derecho positivo tenga en esa actualidad un poder universal sobre todo el orbe (pág. 38). Por consiguiente, el Emperador no tiene ni puede tener ningún título que legitime la conquista de los estados bárbaros de las Indias. Diera esto lugar a polémicas y roces entre el sabio salmantino y Carlos $V$, no es nuestro intento examinarlo (4), pero la conclusión de Vitoria es tajante: 
"El título de supuesto dominio universal del Emperador no justifica la conquista de las Indias" (pág. 39).

$\mathrm{Ni}$ es menos resuelta su conclusión a cargo del Papado. como institución temporal que delega poderes de ocupación. "Saquemos la consecuencia de que los españoles, que primeramente navegaron hacia tierra de bárbaros, ningún título llevaban para ocupar sus provincias" (pág. 47). Conclusión lógica de las premisas teológicas entonces comunes en las escuelas. Pero Vitoria las aplicaba a la vida histórica. Sin embargo, no se ha de exagerar, porque, como luego veremos, el autor admitía la validez por vía indirecta de las intervenciones del poder espiritual. Bajo este aspecto hubiera podido adquirir la gesta de España su legitimación.

Por estos mismos fundamentos, ni el Papa, ni los príncipes por cuenta de él pueden intervenir con las armas, en los desórdenes morales y religiosos de los no cristianos, "ni por autoridad papal" (pág. 61). "Tal potestad supone algo falso, que el Papa tiene jurisdicción sobre ellos" (ibi). Cuando es así que "el Papa no puede legislar sobre los infieles". Nótese que todas estas cosas van dichas para rechazar los excesos del agustinismo político, que parecian envolver la sociedad medieval. Y Vitoria sostiene que se pueden resistir a las cosas malas que hagan los Papas, lo cual granjeó a nuestro autor la condena de sus Relecciones en el Indice de Sixto V, según dice Bonilla y San Martín (5). También en la organización interior de la Iglesia Vitoria, alejándose en algún punto de Santo Tomás, tenía ideas propias sobre obispos, papa y concilio ecuménico. En una palabra, Vitoria aun permaneciendo fiel a la inspiración escolástica no quería someter sin razón los acontecimientos al molde del pasado, fuese éste muy glorioso. Era menester acudir directamente a la razón, la cual explicara el sentido de las nuevas instituciones.

\section{LAS BASES NUEVAS}

Si queremos hallar, en el sedimento de las especulaciones vitorianas sobre Iglesia y estado, el principio base, creo que son éstos: el de la autonomía originaria que pertenece por igual a todos los estados y a la Iglesia en base a principios inmutables, y el paralelismo de las pretensiones jurídicas entre los planos de los varios organismos. Para Vitoria existe la exigencia del perfeccionamiento económico material, lo cual hace nacer el derecho universal primitivo de los ciudadanos y de los estados para cambiar los bienes sin lugar a trabas. A éste corresponde en el campo de la lglesia la exigencia de difundir la verdad religiosa, y por ella el derecho a la predicación. Este sistema de la analogía, lo hago notar, puede facilitar en el Derecho internacional de hoy la tarea de colmar lagunas e ilogicidades de quienes ven una personalidad de la. Iglesia y no saben concederle derechos sur. tantivos.

Podemos aceptar la frase de un escritor del siglo pasado (6) que los escolásticos españoles del siglo XVI, "estaban animados de un espíritu mucho más independiente que los antiguos escolásticos merced a los progresos que el Renacimiento había traído a nuestras escuelas". Con una rara visión, supieron reconocer el gran papel que en la nueva política jugaría el estado territorial, pero fieles a la tradición, reconociencio la au- 
tonomía, no destruyeron la unidad del derecho, derecho único cuyas partes son el sistema interno de cada organismo y la esfera general de las relaciones comunes llamada derecho internacional. $Y$ esto cuando Lutero, suprimiendo el valor de la jerarquía externa de la Igesia preparaba el cam: po al laicismo jurídico y con su criterio de libre examen inauguraba la egolatría de cada estado.

Llama la atención que las fórmulas elaboradas en el retiro de los claustros monacales son hoy reconocidas por autores ajenos a simpatías clericales, como las fundadoras del Derecho internacional. Es verdad que Grocio se aprovechó de Vitoria, sin embargo, hay un hiato ideal muy "profundo entre ambas escuelas. La de Salamanca creía en un principio fundamental absoluto, raíz de la unidad jurídica. El holandés y sus sucesores partían de un contrato. Pero por curiosa paradoja, los modernos, hijos espirituales de Grocio, mejor se hallan en el principio de unidad y sus consecuencias con Vitoria que con el jusnaturalismo. Asi la escuela vienesa de Kelsen cree en un postulado anterior y común a todo principio jurídico, que dá su carácter peculiar a la efectividad de la vida del derecho. Dentro de este molde amplio hay cabida para cualquier sistema de normas y para reconocer como juridica a toda persona que sepa presentarse con las debidas características. Las fórmulas del estatismo excluycnte del siglo pasado han muerto.

El derecho internacional moderno reconoce como una de las exigencias fundamentales de la sociedad de gentes la libertad de penetración civil de un estado en otro, expresión de la convivencia en paz. Esta, hemos afirmado, es la base que Vitoria también aduce, como priniera justificación del trato entre indios y españoles. Para fundamentar su tesis nuestro autor trae a colación el vínculo del origen único y el deber del amor universal; pero reconoce también una relación directa de las perso. nas con el territorio, en cuanto encierre los medios de subsistencia y perfeccionamiento humano. $Y$ aunque un estado por su soberanía y los derechos ya adquiridos pueda reglamentar el uso de dichos bienes, sin embargo, no puede por principio excluir a los extranjeros. Por consiguiente, no sólo tienen los extranjeros el derecho de recorrer, permanecer y comerciar aprovechándose justamente, sino que están en pie de igualdad para la pesca, la caza, por ejemplo. Los hijos nacidos en tierra extranjera tienen derecho a la naturalización (pág. 67, 69, 71, 72). El estado no puede prohibir las iniciativas privadas, ya sean de importación o de exportación; ni vale diferencia para pueblos más cultos o bárbaros. Así quedan todos igualados.

Para entender mejor la mente de Vitoria y despejar el campo, es menester advertir lo siguiente. No tuvo Vitoria ese sentido de titularidad que hoy día nos hemos acostumbrado a concebir alrededor de la entidad estado. La consideración del territorio, como soporte de la soberanía y parte integrante de ese organismo, no aparece. El elemento personal, (es decir, la población), conserva su carácter de masa de individuos y por lo mismo en el mismo campo internacional no sólo hay derechos de los estados, sino de los individuos, con una esfera intangible y con una autonomía superior cuyo respeto es la misión del estado. La misma esencia del derecho se polariza hacia el interés de un individuo o de la colectividad como suma de individuos, sin mirar a la estructura estado, que es para nosotros la expresión jurídica de la sociedad y de la fuente de la ley. Tampoco 
aparecen diferenciados los elementos de derecho público y privado; la soberanía se mira como un bien patrimonial del soberano que guarda en su familia junto con el dominio civil el ejercicio de la jurisdicción. Así nace un duasmo, el principe que tiene la personalidad en el comercio de las raciones y os súbdito: que penden de su poder absoluto. El concepto de estado y órgano esiatal no había nacido. Todo lo cual tiene una importancis puctica grande cuando se trata de destilar en términos modernos $e$ l pensemier to cenuino y verdadero del autor, contraponiéndolo a las corsecuencias que derivan lógicamento de sus principios, pero que a lo me. jo. no fueron vata por inmadure? de bs tempos. En esta cuestión que

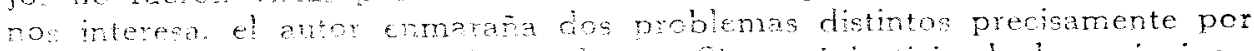

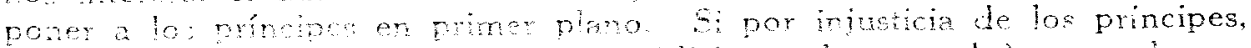

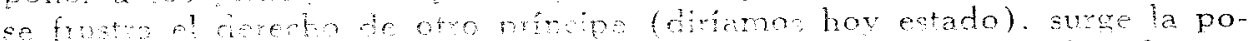

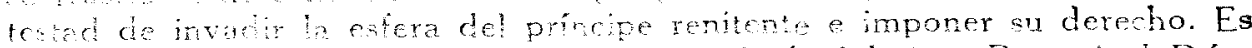
ei rato como veremos de la peretración de la frlesia Pero si el Prín-

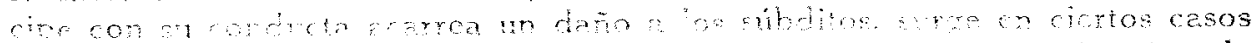
el derecho de lo mincipes a intervenix, poro no entess propio, sino de

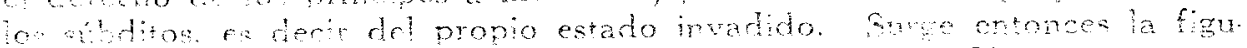

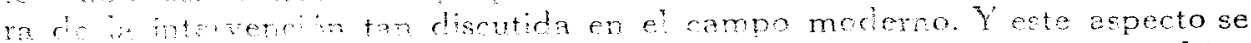
presenta tambien en el caso de la predicación de la lolesia que es un bien

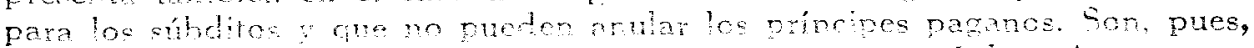
dos cuectiones muy distintas. A nosotros nos interesará la primera, que versa sobre e! interes de la propia lolesia.

\section{LA EXPANSION DE LA IGLESIA (Contenido de su potestad jurisdiccional)}

Vamos a ocuparnos de lo que pensó Vitoria sobre el derecho de expansión de la Iglesia en los estados no católicos.

El problema es muy amplio en su aspecto general, los derechos de la Iglesia frente a un estado, fuere pagano, fuere cristiano no católico. Vitoria sólo consideró un problema histórico-político concreto, y entre varios aspectos de éste habló de la evangelización; pero los principios, como bien se comprende, tienen valor universal e implícitamente resuelven también el caso de los estados herejes o cismáticos o sólo de facto cristianos.

Nuestro autor trata de justificar la conquista española de las Indias en la Relección primera "De Indis", y después de haber rechazado siete tíkulos ilegítimos, pone otros siete de valor jurídico real y un octavo cuya apreciación deja en suspenso. El primero de los legítimos es el derecho de expansión comercial, que puede llegar hasta la conquista de la sobera. nía, si los Indios lo obstaculizan. El segundo, tercero y cuarto se relacionan con la penetración y libertad del culto cristiano. El quinto es un caso de intervención en favor de inocentes. El sexto y séptimo se refieren a convenios. La idea general en todos ellos es la misma: si los bárbaros respetan el derecho, no se puede disminuir su soberanía; en caso contrario, surge en los españoles el derecho de acudir a la fuerza, con la debida proporción, que puede llegar hasta a colonizarlos.

A propósito del segundo título, sienta esta primera proposición: "Los cristianos tienen el derecho de predicar y anunciar el Evangelio entre 
los bárbaros" (pág. 76). He aquí sus fundamentos: la Sagrada Escritura "Fredicad el Evangelio a toda creatura" (Mc. XVI, 15). Es como se ve, una base teológica, universal y entonces admitida por todos los juristas cristianos y aun por los teólogos pseudo-reformadores. Otra razón aparentemente muy importante es que, "si tienen derecho los españoles de peregrinar entre los bárbaros y negociar con ellos, lo tienen también de anunciar la verdad a los que quieran oírles, principalmente la verdad relativa a la salvación y felicidad antes que la relativa a cualquier otro género de conocimientos humanos" (pág. 77). He dicho aparentemente, porque, si bien el paralelismo con el derecho de expansión comercial está claro, así como la solidaridad moral e intelectual de pueblos tan lejanos, sin embargo, es el derecho de predicar a los que tienen derecho de oír, y por tanto, es un caso de intervención en favor de aquéllos que quieren, pero son impedidos. Sigue otro motivo teórico, el universalismo saivador de Cristo que trae corsigo como medio necesario el derecho de predicación, y por último la obligación de caridad de guiar a los que están en el error, pero tampoco este motivo funda un derecho contra estado infiel.

Para comprender la naturaleza de este derecho es menester compulsar la Relección "De potestate Ecclesiae Prima", en la cual se ventilan

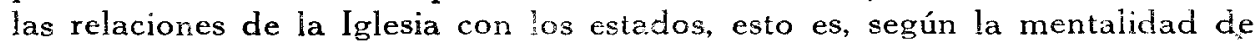
Vitoria con los estados cristianos. Pero a la postre idéntico es el fundamento: "Predicad el Evangelio...". Es éste un mandato precisamente en orden a la expansión; de aquí se sigue que la Iglesia tiene un derecho directo a que los estados abran la esfera de sus territorios a la predicación. (Por consiguiente, la Iglesia tiene un poder propio sobre todo el mundo (pág. 265). No se trata, según diremos después, de una atribución derivada por la violación de un estado, sino de una prerrogativa que se des. prende de la misma esencia de la personalidad católica de la Iglesia. Son éstas, conclusiones que sacamos nosotros, pero que manan del enfoque victoriano, y cuya fuerza se ve confirmada por los hechos actuales.

Dirá alguno que el titular del derecho de la predicación son "los cristianos", pero no la Iglesia como colectividad. La respuesta contraria se halla en los fundamentos teológicos que se refieren a la Iglesia docente; pero además dice el autor que "aun cuando lo precedente sea lícito a todos, no obstante puede el Papa confiar el negocio a los españoles y prohibirlo a los demás" (pág. 77), pues "corresponde al Papa especialmente la divulgación del Evangelio por todo el mundo" (ibi), antes bien puede el Papa hasta prohibir a los otros príncipes cristianos el ejercicio del derecho ide comercio en cuanto sea necesario a la evangelización. Todo lo cual demuestra que el derecho está en las manos de la Iglesia como tal.

Nos ocuparemos luego de los límites de esta facultad al tratar de la esfera de soberanía estatal que la Iglesia no puede invadir. Veamos aquí someramente el objeto de la evangelización. Vitoria habla de ellos en forma amplia, y sólo menciona expresamente la predicación, pero recrimina alguna vez (pág. 58) que las obras de los colonizadores no hayan constituído esa reprueba de la verdad necesaria para la aceptación de la fe. Es decir, no parece exagerado decir que Vitoria comprende en esa prerrogativa de expansión la exposición y realización integral de la vida oristiana con sus obras de instrucción, beneficencia, caridad, como motivo de le credibilidad, las cuales tienen su correlativo en el derecho de expansión comercial, que él reconoce tan ampliamente. 
Pero hay una frase que hemos referido antes, la cual parece negar lo expuesto y ha sido ocasión de disputa en la controversia Getirn-Andrés. acerca del juicio de Vitoria sobre la juridicidad de la conquista española. Habiando del poder del Papa acerca de los infieles y de la posibilidad de una delegación, nuestro teólogo concluye: "Saquemos la consecuencia de que los españoles que primeramente navegaron hacia tierra de bárbaros, ningún título lievaban para ocupar sus provincias". (p. 47).

Quizás la frase no sea genuina, como sostiene Andrés, pero tiene un sentido perfectamente legítimo, pues se halla colocada a fropósito c: " poder temporal del Papa; luego, es verdad que los españoles no tenían ti. tulo por esta parte. Lo mismo se ha de decir a propósito de las Buias de demameis de Alejandio Vl (pán 39). cuyo vio implicitameste rochas. Pero en a Rececón De Ecclesia vueive a hablar de las miamas (pág. 277) y las interpreta como una de esas provitencias polleco que el Papa tiene derecho a dictar por la necesidad de la fe. Adomás, loa españoles habían verificado fuertes desembolsos para la conquista y evan. gelización y por consiguiente era justa la concesion de exchiviva rente a los otros príncipes cristianos. De la posibilidad de tal reparto habla en concreto ruestro autor a propósito de las posesiones de los musulmanes (cfr. pég. 78). "Así como para conservar la paz entre los Principes cris. tianos y ensanchar la religión, pudo el Papa de tal modo reparír las provincias de los mahometanos entre ellos, que uno no pasase a la parte del otro, as tambien potía en beneficio de la religión consituir principes, principalmente alli donde antes no los había cristianos".

Entramos, pues, en otro aspecto del problema: icuáles son las relaciones del estado evangelizador frente a la lglesia por una parte y al eslado pagano por la otra? Para entender lo primero, es menester libar algo sobre la concepción del teólogo español acerca de la sociedad cristiana.

Vitoria acepta la base agustinista, tan cara a la Edad Media, pero niega a la vez toda dependencia directa del estado, que tiene una soberanía originaria y perfecta, como la de la iglesia. "Cristo dejó en la Iglesia una, dos potestades distintas para la conservación e incremento de los bienes tanto temporales, como espirituales" (p. 270).

No obstante la independencia de los organismos, Vitoria afima la dependencia de los fines. Estos son subordinados, y por consiguiente delimitan la esfera de acción jurídica, aunque el depositario de la soberanía conserve su independencia; es él el que ha de reconocer estos límites y el que ha de jcrarquizar su acción para salvar la subordinación de su fin a los otros superiores. Sólo en cuanto el organismo inferior descuide positivamente esa subordinación y lesione asi gravemente la esfera del superior, (superior por razón de un fin más noble, ro por autoridad), dicho superior haila en el principio de sus exigencias vitales el resorte que amplia sa sobe ranía hasta donde sea necesario para destruir el peligro. Se trata del estado de necesidad.

Esto mismo dígalo Vitoria con sus palabras: "Toda la Iolesia es un sólo cuerpo y no dos por la república civil y por la espirituai, sino uno solo, como $\epsilon$ s cierto según el apóstol S. Pablo, en cuanto que Cristo es cabeza de toda la Iglesia; y fuera monstruoso o que un cuerpo estuviera sin cabeza o que una cabeza tuviera dos cuexpos; sino que en un cuerpo todo está mutuamente unido y determinado y las partes más innobles son por las más nobles. Luego también en la república cristiana todo está su- 
bordinado $y$ unido, oficios $y$ fines $y$ potestades, $y$ de ningún modo puede decirse que lo espiritual es por lo temporal. Por tanto, lo temporal es por lo espiritual y depende de ello". (pág. 264-5).

Vitoria invoca, para aclarar el concepto, el tan acertado principio de la analogía entre la sociedad civil y religiosa. Todo lo que puede la primera, lo puede también la segunda en su campo. "La razón de todo esto es, que la república espiritual debe ser perfecta como la temporal y por tanto suficiente a sí misma; ahora bien, la república temporal tiene este derecho, que si de otro modo no puede conservarse indemne e incólume, puede ejercer jurisdicción y autoridad; por ejemplo, si los españoles no pudiesen de otro modo defenderse de las injusticias de los franceses, podrían ocupar sus ciudades, darles nuevos soberanos y príncipes y castigar a los culpables $y$ hacer otras cosas por propia autoridad como si fuesen. sus -verdaderos señores, como todos los autores tienen que confesar. Luego, del mismo modo, si la potestad espiritual no puede de otro modo conservarse indemne y conservar indemne a su república, podrá hacer por propia autoridad todo lo necesario para aquel fin; de lo contrario, fuera manca e insuficentemente constituída para su propio fin". (pág. 268-9).

Lo más notable de este párrafo es que la potéstad sobre el estado no es una sustitución de órganos dentro de la autonomía estatal, sino es la prolongación del propio poder jurisdiccional de la entidad Iglesia, que comprime, digamos así, por su virtud expansiva, la esfera del estado. Toda violación del derecho pone a la persona autora de la violación en un lugar de inferioridad y crea en el ofendido un poder de resarcirse jurídicamente a costa de la primera, sin que ésta pueda estorbar. Este poder llega hasta a sustituirse en los propios derechos del ofensor y hacerlos efectivos a su propio provecho. Sin embargo, estas pretensiones hallan límite en cierta proporción que ha de salvarse sobre todo y que responde a lo limitado de los fines propios de cada estado. Pero en el caso de la Iglesia, por razón del fin, universal y superior, según nota Vitoria, esta expansibilidad de la soberanía alarga de mucho los alcances, hasta llegar teóricamente a poder modificar la estructura constitucional de los estados, que en alguna manera son parte de esa misma Iglesia. Y así se explican esas frases tan fuertes, que la Iglesia "puede no sólo lo que los príncipes seglares pueden, sino también hacer nuevos príncipes y quitar a otros y dividir los imperios y otras muchas cosas" (pág. 266).

Sin embargo, este poder omnímodo no nace sino cuando la acción antijurídica del estado católico o el estado de necesidad de la Iglesia toda - parte notable de ella lo hacen necesario para evitar un mal muy grave. No se trata, por consiguiente, de que el Papado exija obras que sean útiles o provechosas para la Religión, sino de situaciones en que peligra el ser mismo de parte de la Iglesia. Además, dice Vitoria, la facultad de la Iglesia en tales circunstancias no la autoriza a movilizar directamente las energías temporales del estado, sino a exigir a éste que las ponga en acción, y sólo en cuanto dicho estado no quiera ejercer su función discrecional, puede la Iglesia sustituirse y directamente convocar hombres y granjear medios materiales para llevar a cabo las campañas necesarias a su salvación. Entonces los súbditos de los estados estarían obligados con estricto deber jurídico a acatar las ordenanzas de la Iglesia, aunque ellas carecieran de coacción suficiente material.

Por estos principios puede la Iglesia obligar a la paz a dos estados 
cristianos beligerantes "a fin de evitar los graves males espirituales siempre consiguientes a las guerras entre príncipes cristianos" (pág. 44). De tal base también se deriva el reparto hecho entre España y Fortugal de las tieras americanas, serin entez se dijo (pág. 277). Fn tales casos de necesidad puede el Ponfice hacer "cuanto es necesario para quitar el escándalo del con paxa la protecón de la religión contra los paganos y para fres perrio:" (pág. 276). Implicitumente se ve claro el pensa monlo te crow anor de que el Papa pude obligar a los Principes a

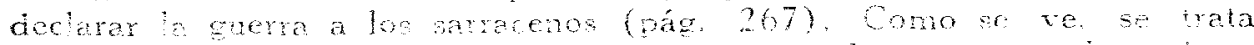

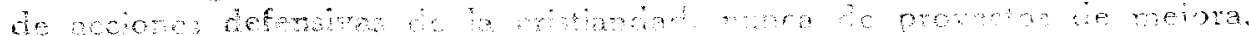

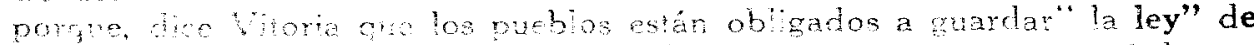

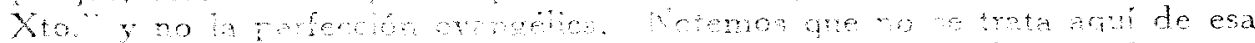

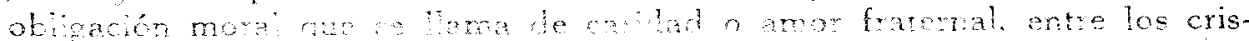

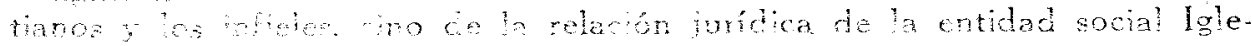
sio an la crided estado cristiano.

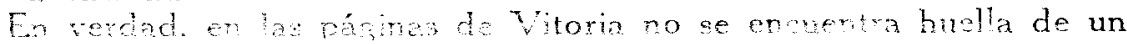
poder de la lglesia cue cbligue a un estado a ser emisario y sostén de su expansion. Podrá sumir corcionte obligación, cuando ia iglecia tenga que sostener con medios coercitios la expansión que ella pacíficamente había empezado y que el estado ro cristizno imoide; pero en sa strosición la raíz es una violación del derecho de la Iglesia y la necesidad de impedir que le venga un daño mayor al no repeler a arción antjuridica del infiel. En todos los casos la apreciación de la necesidad está en el criterio del Papa (por anajogía al caso que resuelve Vitoria en la pág. 270 ).

El caso corriente será el que un estado espontáneamente asuma el encargo de la evangelización. Así, revistiéndose de las prerrogativas de la fe católica, goza del derecho de enviar predicadores e instalar las obras de bien social, según se ha dicho, a la vez que puede dedicarse por su derecho propio a las utilidades del comercio. Luego veremos el límite de tales atribuciones. Pero si el príncipe infiel defrauda estos derechos, surge Ia acción para sostener los intereses religiosos y civiles hasta llegar a menguar y absorber la soberanía de tal pueblo. Vitoria no dice quién será el nuevo titular de la soberanía, pero del conjunto de la obra aparece ciarísimo que ni siquiera dudó del problema. Porque, aunque el interés que fundamenta la acción ocupadora de la soberanía es de la esfera de la Iglesia católica, sin embargo, no es menos verdad que la Iglesia no debe poseer dominios temporales, sino en cuanto son necesarios al ejercicio de su poder espiritual; por consiguiente, hasta que no apereciere convenio expreso, se ha de pensar que los despojos son de aquel que puso armas y hombres y el esfuerzo, esto es del estado evangelizador. Por esto, dice muy bien Vitoria que uno de los títulos por los que pudieron venir los indios al po der de los españoles era la propagación de la religión cristiena. Hay mảs. nuestro teólogo considera, según se ha visto antes, la expedición misionera, como derecho de los cristianos, que tienen este principio de la catolicidad sntre los de su orden público, y ve al poder del Papa, como elemento de control.

Nada nos dice Vitoria del contenido de obligaciones de! estado co lonizador ni de los derechos de exriuir a otros países, a no ser que medien pactos entre las dos potestades. Como e? probiema para el era legitimar Ia expedición política de españoles contro indios no es raro su silencio. Además él no conoció laz soluciones más concretas de la época de Felipe II. 


\title{
LOS LIMITES DEL DERECHO DE EXPANSION DE LA IGLESIA.
}

\author{
(Zona de autonomía exclusiva del estado soberano).
}

Después de haber considerado la naturaleza del derecho de expansión de la Iglesia dentro del estado no cristiano, resta brevemente considerar sus límites. Vitoria considera tres casos: el primero, un estado comple.. tamente infiel, del cual nos hemos venido ocupando hasta ahora; el segundo, una minoría cristianizada, y el tercero, una "buena parte" de la masa de población, convertida. Estos dos últimos son otros títulos por los cuales se pudiera legitimar la conquista española de América por lo menos en la situación de hecho contemporánea al autor y son dos aspectos que suponen el desarrollo del primero.

En el estado plenamente infiel se concede a la Iglesia el derecho de hacer oír la verdad revelada por los medios normales, sin que sea legítima ninguna coacción. La predicación debe ser congrua y acompañada por pruebas fehacientes y confirmada por la experiencia de ser conforme a la vida racional. Esto es, Vitoria concede dentro del campo territorial infiel la gar rantía de tna pasividad de parte del estado, un mero non-facere, que consiste en no impedir la difusión de las doctrinas cristianas y en no poner en inferioridad civil social a los que las aceptaren. Si realizada esta tarea, la fe no arraiga, no se puede proceder por la violencia a la conversión (pags. 78,79).

Sin embargo, Vitoria pone a cargo de los "barbaros" dos obligaciones. Aunque no se debe creer sin pruebas, hay obligación de oír en materia de religión, cuando sus propios conocimientos no explican racionalmente el problema de Dios (pag. 57). Hay obligación de aceptar las doctrinas predicadas, cuando son propuestas con argumentos razonables y corroboradas, según he dicho antes, por el ejemplo de una vida digna del hombre (pag. 58). Sin embargo el Papa no tiene acción jurídica si los indios no quieren cumplir y acatar (p. 45-6 58-9).

La doctrina vitoriana es de gran limidez y dá la clave para superar un obstáculo legal muy serio: los principios de orden público del estado pagano. La historia enseña que los pueblos paganos todos tienen estructurada su vida publica sobre la confesión religiosa de manera que predicar la falsedad de ésta es atentar a sus bases jurídicas. Pero Vitoria supone que tales bases no solucionan adecuadamente el problema de Dios, y por consiguiente esa colectividad tiene a su cargo el deber de buscar una solución más perfecta es decir una superación de lo incompleto o defectuoso de surs instituciones, pues la revelación cristiana se presenta no como negación de las instituciones jurídicas naturales, sino como una ampliación de las bases racionales por leyes positivas emanadas del propio autor del orden natural del derecho. De manera que la Iglesia tiene derecho de mantener sus pretensiones frente a las aberraciones religiosas de un estado pagano, aunque fueran la base de la constitución. Se podría aducir como analogía (ajena por completo al pensamiento de nuestro teólogo) el caso de un estado que surgiera hoy y pretendiera desconocer los derechos acordados por unánime y tradicional acuerdo de los estados. Sobre el" fundamento de los derechos del hombre estas conclusiones se hallan virtualmente contenidas en Vitoria. 
Si tales derechos de la Iglesia no son reconocidos ni pueden llevarse a cabo en forma eficaz por deslealtad de los príncipes no cristianos, los cristianos pueden reintegrar su derecho con las armas, en cuanto sea suficiente a garantizar la expansión sin llegar a la absorción de la soberanía excepto el caso de una injusticia irremediable por la mala fe persistente o en castigo de atroces crímenes cometidos (pag. 134.- Relección de jure beIli Hispanorim in barbaros). De hecho, agregaré yo que la Iglesia nunca ha llegado a tales extremos. Nótese bien que Vitoria claramente excluye que se pueda absorber o disminuir la soberanía del estado, si la expansión de la Iglesia, es decir todo lo que contribuye a la predicación, se puede garantizar por medios menos drásticos. Y en todo caso, como los súbditos no tienen responsabilidad de las injusticias de los príncipes, los españoles, aunque llegaran a la ocupación deben proceder teniendo en cuenta el bien de los indios (pag. 79).

Si en un estado pagano se ha formado una minorỉa de religión cristiana, a todas las prerrogativas de antes se añade un cariz especial. Este nuevo título "es no sólo de religión, sino de amistad y sociedad humana, pues por el hecho de haberse convertido algunos bárbaros a la religión cristiana, son amigos y compañeros de los cristianos, y debemos procurar a bien de todos, pero principalmente el de nuestros hermanos en la fe" (pag. 80).

Interpretemos en términos modernos estas palabras. Nos ha dicho Vitoria que las sociedades eclesiástica y civil forman un sólo cuerpo bajo una sola cabeza. Sabemos, por otra parte, que el bautismo es el acto que hace nacer el vínculo y la incorporación en la sociedad sobrenatural y externa que se llama Iglesia. Por consiguiente, esa minoría pagana pertenece a esa sociedad y tiene los derechos de ser socorrida por el conjunto. Todo príncipe cristiano, pues, puede, antes bien está obligado a ayudarla a perseverar en su calidad de cristiana, repeliendo los obstáculos y los ataques. De las palabras de Vitoria en este segundo caso sólo se saca un derecho de defensa que ya estaba contenido en los principios del anterior, pero da gusto ver que el alavés percibe en todas sus consecuencias el "status" jurídico de bautizado perseguido, en todo análogo al de los ciudadanos que se hallan vejados en un país extranjero.

Pasemos al tercer caso. Dice así: "Si buena parte de los bárbaros se hubiesen convertido al cristianismo, ya violentados ya espontáneamente, mientras sean verdaderos cristianos, puede el Papa darles, con cansa justa, lo mismo a petición de ellos que voluntariamente, un príncipe cristiano $y$ quitarles los señores paganos" (pag. 81). No nos detendremos sobre las razones que el autor alega para probar su tesis. En cambio estudiemos los varios elementos de la proposición.

No aclara nuestro teólogo lo que entiende por "buena parte". En el texto latino dice: "bona pars" sin precisar mis, pero comparando esto con el caso de la minoría, se ha de entender que por lo menos la mitad de la población se ha convertido aunque lo fuera violentamente, porque entonces como súbditos del Romano Pontífice, pueden ser objeto de su poder directo. Pero lo que diferencia este caso de los demás, es que no se hace mención de atropellos que den lugar a la legítima defensa como en el anterior o a la revancha como en el primero, sino que el Papa con causa justa puede llegar a cambiar la autoridad suprema del estado que en parte es pagano. No hay duda que también aquí el Papa procede para garantizar 
la fe y por ende mediante el uso de su potestad temporal derivada de la espiritual, pero la razón inmediata quizás sea la gran inconveniencia de que una población católica esté sujeta a una autoridad no cristiana con peligro real de injusticias o por lo menos de oposición solapada. Esto parece der ducirse del texto: "si así conviniese para la conservación de la religión cristiana por temor a que los nuevos cristianos apostatasen bajo la dominación de señores paganos o fuesen por su conversión vejados, sabido es que en favor de la fe puede el Papa cambiar los Señores paganos". (pag. 81) Esa justa causa, pues, parece ser "el peligro" que ya normalmente por la malicia humana va anexo a la coyuntura de jefes no cristianos, pues si bien no persiguieran abierta o cruelmente la religión, siempre con sus leyes de moralidad inferior constituirían por lo menos en la generalidad de los casos un peligro grave para la comunidad de neo-conversos. Es pues a la postre también este un caso de defensa de la Iglesia. I esto basta para abrir una brecha en la obediencia que también los proncipes malos se merecen.

Este es el máximo poder que Vitoria concede al jefe de la Iglesia dentro de un estado que esta fuera de la órbita cristiana. Se trata, es verdad, de una facultad ejercida directamente sobre los súbditos católicos de ese estado y con la mira exclusiva de darles a ellos un jefe temporal que salvaguarde su calidad de cristianos. Pero como no es posible crear un estado a parte, he aquí que por la conexión ineludible de los hechos, la parte infiel tiene que someterse a las exigencias de la parte mayor que es cristiana, según el principio de Vitoria que en las cosas de gobierno lo que quiere la mayor parte es lo que se debe imponer a la totalidad. Queda por tanto semetido el estado pagano por fuerza de las circunstancias a la autoridad de la Iglesia.

Pero aunque teóricamente esto sea un derecho de emergencia al borde de la potestad eclesiástica, sin embargo da al poder de la Iglesia una gran extensión. Hoy los estados son oficialmente laicos, o mejor indiferentes a las varias formas de religión positiva, pero su población es de hecho católica. Por lo mismo pudiera la Iglesia intervenir cuando un gobierno anticlerical pusiese en peligro lo sustancial en la vida religiosa de los ciudadanos para defender su derecho de subsistir.

¿Qué diría Vitoria si compareciera a juzgar la actual sociedad internacional? Mantendría sus principios, antes bien hallaría que hoy menos trabas jurídicas se oponen a su realización. En los tiempos de la Reforma el ardor de las sectas hacía de cada estado un baluarte de oposición religiosa, ahora habiéndose declarado el estado indiferente, porque es incompetente en materia de religión, ha dejado el campo libre para que avance en el nuevo derecho la Iglesia católica. Los hechos están demostrando que mientras el agnosticismo oficial en materia religiosa crecía, la autoridad de la Iglesia se ha ido concretando en fórmulas jurídicas y relaciones diplomáticas con los estados de toda confesión. Sin necesidad de fuerza la Iglesia ha podido mandar sus emisarios de avanzada, y prácticamente en todo el mundo lleva a cabo su tarea esencial de expansión. 


\section{CONCLUSIONES} guientes:

De estos breves apuntes, cuemos legitimas las conclusiones si-

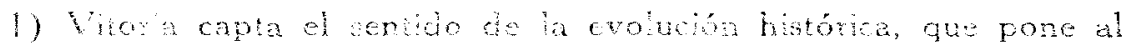

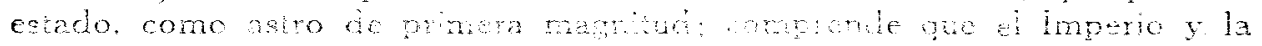

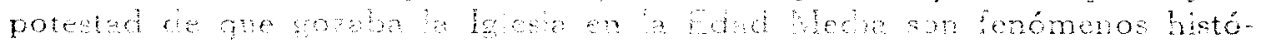

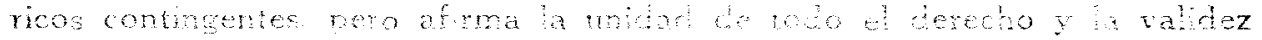
abscha de su unin base.

2) Afmor la autonomía origira del estado, y a través dé param lelino busa a bave de la exparion de los ectados y la lgiesia en sus campos. Determina el empuje dinérioo de las dos poiestades y allana sus interferencias $y$ su cubordinación. Fija también los principios en matera de intervención.

3) Sin embargo, su concepto de estado no es maduro. Los "plínci. pes" tiguran en primer término en lugar del estado, como litular de la juridicidad. Por lo mismo se confunden las cuestiones de derecho privado con el aspecio público de la soberanía. El enlace de la potestad estatal con el territorio casi no aparece, y el derecho es un poder moral sin que el elemento tierra lo condicione. La población no es uno de los elementos con carácter de unidad, sino es una suma de individuos. Tampoco aparece esa distinción, tan neta en el derecho moderno, entre "los principes cristianos" y la Iglesia.

4) Vitoria otorga a la Iglesia un derecho de expansión universal, de naturaleza espiritual, capaz de prevalecer contra intereses temporales por su propia virtud expansiva sin que constituya destrucción de la esfera estatal, sino simple cesación del poder jurídico del estado en vista del fin jerarquicamente superior en ese caso concreto.

5) Aunque los "príncipes cristianos" son los que aparecen en los documentos vitorianos, sin embarco aparece claro que la titularidad de la expansión católica redunda en la Iglesia, como tal. En el esiado evangelizador hay un doble interés religioso, uno propio por ser el cristianismo parte de sus principios de orden público, otro por ser dicho estado el mandatario o sestor de la Iglesia. Si bien la Iglesia sobre el estado católico pueda en algunos casos alegar pretensiones a un facere positivo, sin embargo Vitoria no admite que el estado católico sea compelido a aceptar una misión cvangelizadora.

6) La penetración de la Iglesia en el estado pagano tiene como contenido la hibre manifestación de las ideas cristianas, sin ninguna sombra de coacción. El estado pagano tiene una obligación meramente negativa de no poner trabas, no vejar ni solapadamente a ios convertidos; tiene además el deber moral de aceptar dichas doctrinas cuando je son propuestas con las debidas pruebas, pero la Iglesia no tiene poder jurídico para cos- 
treñirlo si las rechaza aún en ese caso. La Iglesia, puede proteger sus prerrogativas si el estado las burla; pero sólo subsidiariamente y sólo en cuanto sea necesario a la predicación. En casos extremos puede llegár a anular la soberanía del estado infiel.

7) Si se logra constituir una minoría religiosa católica, la Iglesia al título de su expansión agrega el que proviene del vínculo personal entre ella y esos súbditos, los cuales pueden ser defendidos por los otros cristianos; título, pues, de solidaridad.

Si "buena parte" de la población se ha convertido, la Iglesia ad. quiere un poder sobre todo el estado en cuanto una justa causa se presente, pudiendo llegar a alterar el gobierno constituido.

8) Los principios colocados por Vitoria pueden ser aplicados en el mundo jurídico moderno de hoy. Puesto el principio de la aconfesionalidad del estacio, la Iglesia de facto se ha adueñado de la esfera religiosa como de un campo de compecencia propia y así por esta otra vía se ha forjado en el campo de los hechos concretos una soberanía análoga a la del estado.

La amplitud de las fórmulas a que ha llegado la doctrina internacionalista moderna, rechazando el derecho interno y la soberanía personal del estado como fuente de las normas internacionales, también deja el campo libre a las doctrinas vitorianas. Las relaciones diplomáticas de la Santa Sede y su expansión de facto en todo el murido sólo hallan una explicación plausible dentro del molde del teólogo español y de los que aceptan sus presupuestos.

\section{Por tanto:}

El pensamiento de Vitoria en el problema de la expansión de la Iglesia es fecundo y es moderno.

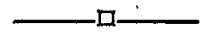

\section{NOTAS}

(1) Relecciones del P. Maestro Fr. Francisco Vitoria. edición por el P. Luis Alonso Getino (cfr. Bibliografía), Introducción pag. XV.

(2) Menendez y Pelayo.- Contestación al discurso de entrada en la Academia de la Historia de D. Eduardo Hinojosa.

(3) De una vez para siempre, citaré entre paréntesis sin otra indicación que la página, las Relecciones. Según digo en la Bibliografía cito conforme a la traducción de Torrubiano.

(4) Entiéndase que evitamos toda apreciación de facto, materia de la polémica entre el P. Getino y el Dr. Andrés Marco, cómo Vitoria juzgó la legitimidad de la conquista americana. Sólo miramos a extractar el jugo de los enfoques jurídicos abstractos. 
(5) Traducción de Torrubiano, Prólogo en la página cuarta.

(6) Mackintosh, jurista inglés del siglo pasado, citado por Bonilla y San Martín, en el Prólogo a que se refiere la nota (5).

(7) Niega la autenticidad de este texto el Dr. Andrés, en su obra "Vitoria y Carlos V. en la soberanía hispano-americana" Salamanca 1937, pag. 57, No 31 .

\section{BIBLIOGRAFIA}

TEXTO:

Relecciones Teológicas, del Maestro Fr. Francisco de Vitoria. Edición por el P. Maestro Fr. Luis Alonso Getino O. P. - Madrid, Valencia. - Feda 1934, Vol. I, II.

Relecciones Teológicas, vertidas al castellano, por D. Jaime Torrubiano Ripoll. - Madrid. - Librería religiosa Hernández 1917.

Nota. - Las citas del texto vitoriano usadas en el presente estudio, son conformes a esta segunda traducción, que responde a la Edición en latín hecha en Madrid en 1765, la que acepta el P. Getino para su traducción (Vol. II).

DOCTRINA : $\mathrm{y}$ siguientes.

Anuario de la Asociación Francisco de Vitoria.- Valladolid 1928

Vol. I. Lecciones sobre Francisco Vitoria fundador del Derecho Internacional (Camilo Barcia, Isidro Beato Salas).

Lasala y Llamas, Manuel. - Conceptos y principios fundamentales del Derecho de gentes según la doctrina del P. Vitoria.

Fernández Prida, Joaquín.-Ultimos justificantes de la soberanía.

Vol. II. - Beltrán de Heredia, Fr. Vicente (O. P.). - - Ideas del P. Vitoria sobre la colonización de América según documentos inéditos.

Nota: Siendo el objetivo de este trabajo el relacionar el pensamiento de Vitoria, sesún se desprende del puro texto con las orientaciones actiales cobre lolesia y Estado en el Derecho Internacional, huelga indicar más detalles bibliográficos.

Estos se hallan cuidadosamente anotedos en e! folleto del doctor Teodoro Andrés. "Vitoria y Carlos $V$ en la soberanía hispano-america na". Salamanca 1937. 